\title{
Role of Health Literacy in Health-Related Information-Seeking Behavior Online: Cross-sectional Study
}

Hee Yun Lee ${ }^{1}$, MSW, PhD; Seok Won Jin², PhD; Carrie Henning-Smith ${ }^{3}$, PhD; Jongwook Lee ${ }^{4}$, PhD; Jaegoo Lee ${ }^{5}$, $\mathrm{PhD}$

\footnotetext{
${ }^{1}$ School of Social Work, The University of Alabama, Tuscaloosa, AL, United States

${ }^{2}$ School of Social Work, University of Memphis, Memphis, TN, United States

${ }^{3}$ School of Public Health, University of Minnesota, Minneapolis, MN, United States

${ }^{4}$ Department of Global Health and Population, Harvard T H Chan School of Public Health, Harvard University, Boston, MA, United States

${ }^{5}$ School of Social Work, Jackson State University, Jackson, MS, United States
}

\author{
Corresponding Author: \\ Jongwook Lee, PhD \\ Department of Global Health and Population \\ Harvard T H Chan School of Public Health \\ Harvard University \\ 677 Huntington Ave \\ Boston, MA, 02115 \\ United States \\ Phone: 16174321232 \\ Email: jongwook lee@hsph.harvard.edu
}

\section{Abstract}

Background: The internet has emerged as a main venue of health information delivery and health-related activities. However, few studies have examined how health literacy determines online health-related behavior.

Objective: The aim of this study was to investigate the current level of health-related information-seeking using the internet and how health literacy, access to technology, and sociodemographic characteristics impact health-related information-seeking behavior.

Methods: We conducted a cross-sectional study through a survey with Minnesotan adults (N=614) to examine their health literacy, access to technology, and health-related information-seeking internet use. We used multivariate regression analysis to assess the relationship between health-related information-seeking on the internet and health literacy and access to technology, controlling for sociodemographic characteristics.

Results: Better health literacy $(\beta=.35$, SE 0.12) and greater access to technological devices (eg, mobile phone and computer or tablet PC; $\beta=.06$, SE 0.19) were both associated with more health-related information-seeking behavior on the internet after adjusting for all other sociodemographic characteristics. Possession of a graduate degree $(\beta=.28$, SE 0.07$)$, female gender $(\beta=.15$, SE 0.05), poor health $(\beta=.22$, SE 0.06), participation in social groups $(\beta=.13$, SE 0.05), and having an annual health exam $(\beta=.35$, SE 0.12) were all associated with online health-related information-seeking.

Conclusions: Our findings indicate that access to online health-related information is not uniformly distributed throughout the population, which may exacerbate disparities in health and health care. Research, policy, and practice attention are needed to address the disparities in access to health information as well as to ensure the quality of the information and improve health literacy.

(J Med Internet Res 2021;23(1):e14088) doi: $\underline{10.2196 / 14088}$

\section{KEYWORDS}

digital divide; health literacy; internet; technology; access 


\section{Introduction}

Health information access and use are essential for optimal health outcomes [1]. For example, a meta-analysis found that health information access and use were associated with better compliance with medical treatment in patients with chronic and acute illnesses [2]. Another study demonstrated that health information access and use are associated with self-care behavior among patients with heart failure [3]. Furthermore, several previous studies revealed that health information access and use predict other health-related behaviors, including having an annual medical checkup and undergoing cancer screenings, because increased cognitive knowledge in health can lead to behavioral outcomes such as receiving preventive screenings [4-6]. This association shows that securing adequate access to and use of health information plays a key role in improving health outcomes in varied domains.

Since its advent, the internet has served as a primary medium to convey health information $[7,8]$. For the last few decades, the dramatic increase in the usage of internet-embedded devices such as laptops, tablets, and smartphones has enabled people to access and use health information at any place and time [9]. According to recent national surveys [10,11], in the United States, approximately three-quarters of adults have broadband internet service at home, nearly $90 \%$ use the internet, nearly two-thirds of adults own a smartphone, and nearly $80 \%$ use the internet for various health-related purposes such as seeking health information, communicating with doctors, and purchasing medicine or vitamins [12-14].

Although the internet has contributed to enhancing the potential for health information access and use while reducing barriers to obtaining health information in the US general population, not all people have obtained these benefits. For example, gender is a key predictor of use of the internet and online health information behavior [15]. Previous studies have shown that men are less likely than women to use the internet for health information-seeking and to trust online sources [13,16-18]. There remain some groups of people who still experience difficulties in accessing and utilizing health information because of barriers such as a digital gap and limited health literacy $[1,19,20]$.

A digital gap is defined as unequal access to technology and capability of its usage [21]. These variations in access to and use of technology often lead to disparities in health outcomes [22]. Existing research shows that predictors of the digital gap include age, gender, education attainment, and income [20]. Closing the digital gap is important because it is significantly associated with the enhancement of health-related decision making, health behavior, and health care system navigation $[23,24]$. In addition to the digital gap, health literacy also influences health information access and use. Health literacy is defined as "the degree to which individuals can obtain, process, understand, and communicate about health-related information needed to make informed health decisions" [25]. Researchers agree on the importance of health literacy in that people with low health literacy are at a high risk of varied poor health outcomes [26-29].
Despite consistent emphasis on the importance of health literacy as a determinant of health outcomes [30,31], and the emergence of the internet as a main venue of health information delivery and health-related activities, few studies have examined how health literacy determines online health-related behaviors such as the usage of the internet for health information-seeking and health-related activities, including online scheduling for visits to clinics. Therefore, this study had a threefold purpose: (1) to investigate the levels of online health-related behavior, (2) to assess whether health literacy is associated with online health-related behavior, and (3) to examine whether sociodemographic characteristics are associated with online health-related behavior. The findings of this study will offer insights into health literacy and sociodemographic-specific interventions for improving online health-related behaviors and health outcomes.

\section{Methods}

\section{Research Design and Data Collection}

The research team collected survey data from 732 adults aged 18 years or older at the 2016 Minnesota State Fair with approval from the University of Minnesota Institutional Review Board. The survey included questions about health literacy and health behavior in addition to general sociodemographic information. Participants received a small gift (a backpack with the University of Minnesota logo, which is worth about US \$3) after they completed their voluntary survey using REDCap software via an iPad. Owing to missing values, data from 614 respondents (241 men and 373 women) out of the original 732 were used in the study as the analytic sample. Comparing the included analytic sample of $614 / 732(83.9 \%)$ to the excluded sample of $118 / 732(16.1 \%)$ due to missing values, we found that people in the included sample, who completed the survey, were more likely to have a family cancer history (included sample: 480/614, 78.2\%; excluded sample: $49 / 76,64.5 \% ; P=.02)$, have both a smartphone and a computer or tablet PC (included sample: 485/614, 79.0\%; excluded sample: $36 / 63,57.1 \% ; P<.001$ ), and use internet for health information (included sample: $549 / 614$, $89.4 \%$; excluded sample: $57 / 74,77.0 \% ; P=.02)$ at the $5 \%$ significance level.

\section{Instruments and Measures}

To measure health-related information-seeking behavior, the main outcome variables of this study were based on two sets of questions about seeking health-related information on the internet. First, a survey question asked whether the respondent used the internet for health information, which was used as a binary outcome variable for health-related internet use. Second, the total score of the 12 health-related internet use items from the Health Information National Trends Survey [32] questionnaire was used to measure the participants' health-related information-seeking internet use score. Each question was assigned a value of 0 (no) or 1 (yes). The Cronbach $\alpha$ of the 12 items for the health-related internet use score was .71. Higher health-related internet use scores indicate more health-related information-seeking behavior using the internet.

The two key independent variables were health literacy and access to technology devices. Health literacy is comprised of 
the total score of the following three health literacy items from the Behavioral Risk Factor Surveillance System Questionnaire [33] developed by the US Centers for Disease Control and Prevention, and was used as the primary measure of health literacy in this study: (1) "How difficult is it for you to get advice or information about health or medical topics if you needed it?" (2) "How difficult is it for you to understand information that doctors, nurses, and other health professionals tell you?" and (3) "You can find written information about health on the internet, in newspapers and magazines, and in brochures in the doctor's office and clinic; in general, how difficult is it for you to understand written health information?" Each health literacy item was measured by a 5-point Likert scale ranging from 1 ("not at all") to 5 ("always"), and the Cronbach $\alpha$ of the three items was .74. Access to technology devices was measured by a categorical variable assessing the type(s) of devices the respondent had access to. Respondents chose one of the following options: "no device," "computer or tablet PC at home," "mobile phone," "mobile phone and computer or tablet PC at home," "smartphone," or "smartphone and computer or tablet PC at home."

In addition to the measures on health literacy and technology devices, the sociodemographic and health information of participants, including gender, age, marital status (never married vs married/partnered), educational level (less than a bachelor's degree, bachelor's degree, or graduate degree and higher), annual health checkup in the past 12 months, any family cancer history, health status (poor/fair vs good/very good/excellent), and participation in a social group, were included as covariates.

\section{Data Analysis}

We first investigated the association of health-related information-seeking internet use with sociodemographic characteristics using $t$ tests for binary variables and $F$ tests for categorical variables with more than two values. We report the Pearson correlation coefficients $(r)$ for continuous variables. In particular, we focused on gender differences in health-related information-seeking internet use because previous studies have shown gender differences in internet use and health information-seeking behavior $[13,15]$. Next, we used multiple regression analyses for both binary and continuous outcome values of health-related internet use. We used logistic regression analysis for binary outcomes and ordinary least-squares regression analysis for the continuous health-related internet use score. We used heteroscedasticity robust standard errors for the multiple regression analyses. We conducted all analyses in Stata 14.1 , using a $5 \%$ statistical significance level criterion.

\section{Results}

\section{Sociodemographic Characteristics and Bivariate Analysis}

Table 1 summarizes the sociodemographic characteristics of the study sample. A total sample of 614 was used in the study, with a majority of women. The mean health-related information-seeking internet use score was significantly higher for women than for men. The mean age of the sample was 41.87 years (SD 16.83), and the correlation between age and health-related internet use score was negligible $(r=0.025, P=.54)$. Only 408 of the 614 participants $(66.4 \%)$ in the sample reported their race/ethnicity.

The total health-related internet use score was significantly different among educational level groups, which was the lowest among individuals with less than a bachelor's degree and was the highest among individuals with a graduate degree. This demonstrates that participants with higher education had higher health-related information-seeking internet use. The majority of respondents indicated having gone for an annual health checkup, and their health-related internet use score was significantly higher than that for those who had not had an annual health checkup. The majority of the sample reported that their health status was good, very good, or excellent; participants with a lower self-reported health status had higher health-related internet use scores than those with a higher self-reported health status.

The majority of the sample had a smartphone and a computer or tablet PC at home, followed by those with a smartphone only. The health-related internet use scores across the different technology device possession groups were significantly different, with the highest scores for those using a smartphone and a computer or tablet PC, followed by the scores for those who possessed a smartphone only. The mean score for those who owned a mobile phone and computer or tablet PC at home was higher than that of respondents who owned a computer or tablet PC only at home or those who had only a mobile phone. The score for those who did not own any technology device was the lowest, as expected. The mean value of the health literacy total score was 12.37 (SD 2.41, range 0-15), and the Pearson correlation coefficient with the health-related internet use score was 0.079 , which is moderate $(P=.04)$. 
Table 1. Sociodemographic characteristics and their relation to health-related internet use of the study sample (N=614).

\begin{tabular}{|c|c|c|c|c|}
\hline \multirow[t]{2}{*}{ Characteristics $^{\mathrm{a}}$} & \multirow[t]{2}{*}{ Value } & \multicolumn{3}{|c|}{ Health-related internet use $\mathrm{b}^{\mathrm{b}}$} \\
\hline & & Mean (SD) & Test statistic ${ }^{c}$ & $P$ value \\
\hline Gender, n (\%) & & & $t_{489.585}=2.95$ & .003 \\
\hline Male & $241(39.3)$ & $3.27(2.49)$ & & \\
\hline Female & $373(60.7)$ & $3.87(2.35)$ & & \\
\hline Marital status, n (\%) & & & $t_{610.169}=1.41$ & .16 \\
\hline Never married or other & $315(51.3)$ & $3.50(2.54)$ & & \\
\hline Married or partnered & $299(48.7)$ & $3.78(2.28)$ & & \\
\hline Educational level, n (\%) & & & $F_{2,611}=14.28$ & $<.001$ \\
\hline Less than bachelor's degree & $197(32.1)$ & $3.06(2.50)$ & & \\
\hline Bachelor's degree & $262(42.7)$ & $3.60(2.31)$ & & \\
\hline Graduate degree & $155(25.2)$ & $4.42(2.30)$ & & \\
\hline Annual health checkup, n (\%) & & & $t_{277.588}=4.31$ & $<.001$ \\
\hline No & $147(23.9)$ & $2.95(2.14)$ & & \\
\hline Yes & $467(76.1)$ & $3.85(2.46)$ & & \\
\hline Family cancer history, n (\%) & & & $t_{200.472}=1.70$ & .09 \\
\hline No & $134(21.8)$ & $3.31(2.57)$ & & \\
\hline Yes & $480(78.2)$ & $3.73(2.37)$ & & \\
\hline Self-reported health status, n (\%) & & & $t_{135.037}=2.81$ & .006 \\
\hline Very poor/poor/fair & $106(17.3)$ & $4.32(2.85)$ & & \\
\hline Good/very good /excellent & $508(82.7)$ & $3.49(2.30)$ & & \\
\hline Participating in a social group, $\mathbf{n}(\%)$ & & & $t_{611.881}=1.81$ & .07 \\
\hline No & $321(52.3)$ & $3.47(2.53)$ & & \\
\hline Yes & $293(47.7)$ & $3.82(2.28)$ & & \\
\hline Technology devices, n (\%) & & & $F_{5608}=6.28$ & $<.001$ \\
\hline No device & $10(1.6)$ & $0.80(1.23)$ & & \\
\hline Computer or tablet PC & $7(1.1)$ & $2.57(2.07)$ & & \\
\hline Mobile phone & $9(1.5)$ & $2.00(1.80)$ & & \\
\hline Mobile phone + computer or tablet PC & $35(5.7)$ & $2.86(2.05)$ & & \\
\hline Smartphone & $68(11.1)$ & $3.13(2.06)$ & & \\
\hline Smartphone + computer or tablet PC & $485(79.0)$ & $3.87(2.46)$ & & \\
\hline
\end{tabular}

${ }^{\mathrm{a}}$ The total sample size of each variable may not be the same as the total sample size of the study due to missing values.

${ }^{\mathrm{b}}$ Based on health-related internet use total score (range 0-12).

${ }^{\mathrm{c}}$ Two-tailed $t$ test assuming unequal variances with Satterthwaite degrees of freedom for binary variables, and $F$ test for categorical variables with more than two values.

Table 2 shows the results of the descriptive analysis on internet use for health information and health-related information-seeking internet use items. For the question asking about internet use for health information, 89.4\% (549/614) of the sample reported that they have used the internet to look for health or medical information for themselves, with a significant gender difference. Among the 12 health-related internet use items, 6 items were significantly different between men and women at the 5\% significance level; women used the internet more for these 6 items, which included "used email or the internet to communicate with a doctor or doctor's office"; "used a website to help you with your diet, weight, or physical activity"; "looked for a health care provider"; "visited a social networking site such as Facebook or LinkedIn to read and share about medical topics"; "kept track of personal health information such as care received, test results, or upcoming medical appointments"; and "looked for health or medical information for someone else.” 
Table 2. Descriptive analysis on health-related internet use.

\begin{tabular}{|c|c|c|c|c|c|}
\hline Question & $\begin{array}{l}\text { Total }(\mathrm{N}=614) \\
\text { mean }(\mathrm{SD})\end{array}$ & $\begin{array}{l}\text { Males }(\mathrm{n}=241) \\
\text { mean }(\mathrm{SD})\end{array}$ & $\begin{array}{l}\text { Females }(n=373) \\
\text { mean }(S D)\end{array}$ & $t$ statistic $(\mathrm{df})^{\mathrm{a}}$ & $P$ value \\
\hline \multicolumn{6}{|l|}{ Internet use for health information (Yes=1, No=0) } \\
\hline $\begin{array}{l}\text { In the past } 12 \text { months, have you used the internet to look for } \\
\text { health or medical information for yourself? }(\mathrm{N}=614)\end{array}$ & $0.89(0.30)$ & $0.83(0.37)$ & $0.93(0.25)$ & $3.63(379.481)$ & $<.001$ \\
\hline \multicolumn{6}{|l|}{ Health-related internet use items ${ }^{b}\left(Y_{e s}=1, N o=0\right)$} \\
\hline Looked for information about quitting smoking $(\mathrm{N}=610)$ & $0.05(0.21)$ & $0.06(0.23)$ & $0.04(0.19)$ & $0.97(447.531)$ & .33 \\
\hline Bought medicine or vitamins online $(\mathrm{N}=610)$ & $0.18(0.38)$ & $0.18(0.39)$ & $0.18(0.39)$ & $0.11(504.817)$ & .91 \\
\hline $\begin{array}{l}\text { Participated in an online support group for people with a } \\
\text { similar health or medical issue }(\mathrm{N}=609)\end{array}$ & $0.06(0.24)$ & $0.054(0.23)$ & $0.06(0.25)$ & $0.65(540.24)$ & .52 \\
\hline $\begin{array}{l}\text { Used email or the internet to communicate with a doctor or } \\
\text { doctor's office }(\mathrm{N}=611)\end{array}$ & $0.46(0.50)$ & $0.39(0.49)$ & $0.51(0.50)$ & $2.91(516.579)$ & .004 \\
\hline $\begin{array}{l}\text { Used a website to help you with your diet, weight, or physical } \\
\text { activity }(\mathrm{N}=611)\end{array}$ & $0.52(0.49)$ & $0.47(0.50)$ & $0.55(0.49)$ & $2.02(505.537)$ & .04 \\
\hline Looked for a health care provider $(\mathrm{N}=608)$ & $0.42(0.49)$ & $0.36(0.48)$ & $0.47(0.50)$ & $2.75(519.359)$ & .006 \\
\hline $\begin{array}{l}\text { Downloaded health-related information to a mobile device } \\
\text { such as an MP3 player, cell phone, tablet computer, or elec- } \\
\text { tronic book device (eg, download mobile apps) }(\mathrm{N}=610)\end{array}$ & $0.28(0.45)$ & $0.30(0.46)$ & $0.27(0.45)$ & $0.64(495.534)$ & .52 \\
\hline $\begin{array}{l}\text { Visited a social networking site such as Facebook or } \\
\text { LinkedIn to read and share about medical topics }(\mathrm{N}=611)\end{array}$ & $0.29(0.45)$ & $0.24(0.43)$ & $0.32(0.47)$ & $2.23(537.405)$ & .03 \\
\hline $\begin{array}{l}\text { Wrote in an online diary or "blog" (ie, web log) about any } \\
\text { type of health topic }(\mathrm{N}=605)\end{array}$ & $0.04(0.19)$ & $0.03(0.18)$ & $0.04(0.20)$ & $0.58(538.839)$ & .56 \\
\hline $\begin{array}{l}\text { Kept track of personal health information such as care re- } \\
\text { ceived, test results, or upcoming medical appointments } \\
(\mathrm{N}=606)\end{array}$ & $0.43(0.50)$ & $0.37(0.48)$ & $0.47(0.50)$ & $2.59(518.015)$ & .01 \\
\hline $\begin{array}{l}\text { Looked for health or medical information for someone else } \\
(\mathrm{N}=599)\end{array}$ & $0.52(0.49)$ & $0.44(0.49)$ & $0.57(0.49)$ & $3.23(497.276)$ & .001 \\
\hline Done anything else health-related on the internet $(\mathrm{N}=610)$ & $0.39(0.48)$ & $0.40(0.49)$ & $0.38(0.49)$ & $0.60(506.309)$ & .55 \\
\hline
\end{tabular}

${ }^{\text {a }}$ Two-tailed $t$ test assuming unequal variances with Satterthwaite degrees of freedom.

${ }^{\mathrm{b}}$ Cronbach $\alpha=.708$.

\section{Multiple Regression Analyses}

Table 3 shows the results of the logistic regression analysis that examined the association of health-related information-seeking internet use with health literacy, sociodemographic factors, and other health-related factors. Women were more likely to use the internet for health-related information-seeking, controlling for other factors, consistent with the bivariate gender comparison for the health-related internet use score (Table 1). Participants who had a postgraduate degree were more likely to use the internet for health-related information-seeking than those who had less than a bachelor's degree. Respondents who had participated in a social group were more likely to use the internet for health information than those who were not in a social group. Respondents with a higher health literacy score were more likely to use the internet for health information. Compared with those who did not have a technology device, those who had a mobile phone and computer or tablet PC at home, those who had a smartphone only, and those who owned a smartphone and computer or tablet PC at home were more likely to use the internet for health-related information. The Wald $\chi^{2}$ test (Wald $\left.\chi_{17}^{2}=53.30, P<.001\right)$ and pseudo $R^{2}(0.15)$ indicated a good model fit to the data. 
Table 3. Multiple regression analyses for factors associated with health-related internet use for binary and continuous outcomes $(\mathrm{N}=614) .{ }^{\mathrm{a}}$

\begin{tabular}{|c|c|c|c|c|}
\hline \multirow[t]{2}{*}{ Variable } & \multicolumn{2}{|c|}{ Internet use for health information ${ }^{b}$} & \multicolumn{2}{|c|}{ Health-related internet use total score ${ }^{c}$} \\
\hline & Odds ratio $(95 \% \mathrm{CI})$ & $P$ value & Regression coefficient (SE) & $P$ value \\
\hline Female (Reference: Male) & $2.68(1.43-5.00)$ & .002 & $0.15(0.05)$ & .007 \\
\hline Age & $1.40(0.95-2.07)$ & .09 & $0.11(0.03)$ & $<.001$ \\
\hline $\mathrm{Age}^{2}$ & $0.99(0.98-1.00)$ & .14 & $-0.002(0.00)$ & $<.001$ \\
\hline $\mathrm{Age}^{3}$ & $1.00(1.00-1.00)$ & .22 & $0.00001(0.00)$ & .002 \\
\hline Married or partnered (Reference: Not married or partnered) & $0.84(0.41-1.71)$ & 63 & $-0.04(0.05)$ & .46 \\
\hline \multicolumn{5}{|l|}{ Education level } \\
\hline Less than bachelor's degree & Reference & $\mathrm{N} / \mathrm{A}^{\mathrm{d}}$ & Reference & N/A \\
\hline Bachelor's degree & $1.19(0.61-2.34)$ & .61 & $0.08(0.06)$ & .18 \\
\hline Graduate degree & $2.99(1.15-7.73)$ & .02 & $0.28(0.07)$ & $<.001$ \\
\hline Annual health checkup (Reference: No annual health checkup) & $1.19(0.61-2.32)$ & .61 & $0.147(0.06)$ & .02 \\
\hline Family cancer history (Reference: No family cancer history) & $1.19(0.63-2.27)$ & .59 & $0.07(0.06)$ & .21 \\
\hline Good/very good/excellent health (Reference: Very bad/bad/fair) & $0.61(0.27-1.40)$ & .24 & $-0.22(0.06)$ & $<.001$ \\
\hline Participating in a social group (Reference: not participating) & $1.90(1.03-3.52)$ & .04 & $0.13(0.05)$ & .008 \\
\hline Log of health literacy total score & $7.19(2.07-25.02)$ & .002 & $0.35(0.12)$ & .004 \\
\hline \multicolumn{5}{|l|}{ Technology devices } \\
\hline No device & Reference & N/A & Reference & N/A \\
\hline Computer or tablet PC & $4.28(0.27-68.49)$ & .31 & $0.43(0.31)$ & .17 \\
\hline Mobile phone & $1.89(0.16-21.81)$ & .61 & $0.42(0.30)$ & .17 \\
\hline Mobile phone + computer or tablet PC & $13.37(1.53-117.09)$ & .02 & $0.60(0.19)$ & .002 \\
\hline Smartphone & $9.77(1.48-64.61)$ & .02 & $0.73(0.18)$ & $<.001$ \\
\hline Smartphone + computer or tablet PC & $8.13(1.49-44.44)$ & .02 & $0.81(0.17)$ & $<.001$ \\
\hline
\end{tabular}

\footnotetext{
${ }^{\mathrm{a}}$ Heterogeneity robust standard errors are used.

${ }^{\mathrm{b}}$ Logistic regression for the dichotomous health-related internet use variable.

${ }^{\mathrm{c}}$ Ordinary least-squares regression for the continuous health-related internet use total score; the natural logarithm of the health-related internet use score was used as the dependent variable.
}

${ }^{\mathrm{d}} \mathrm{N} / \mathrm{A}$ : not applicable.

Table 3 also presents the results from the multiple ordinary least-squares regression analysis that investigated the association of the total health-related internet use score with health literacy, health-related factors, and sociodemographic factors. The health-related internet use score and the health literacy score were transformed using the natural logarithm function, which allowed us to interpret the results in approximate percentage changes in the analysis. Women were also more likely (by $14.50 \%$ ) to have a higher health-related internet use score than men. Age was not significantly associated with the health-related internet use score when we added the age term only; however, age was significantly associated (at a $1 \%$ threshold) with the health-related internet use score when we included quadratic and cubic terms of age in addition to the linear term. This means that age was significantly associated with the health-related internet use score in a cubic manner, whereas there was no linear relationship between age and the health-related internet use score. Solving the cubic equation, we found that the health-related internet use score increased with age until about
38 years, decreased between the ages of 38 and 71 years, and increased again after the age of 71 years.

Respondents who had a postgraduate degree had a nearly $27.5 \%$ higher health-related internet use score than those who had less than a bachelor's degree. Participants who had gone for an annual health checkup in the last 12 months had a nearly $14.7 \%$ higher health-related internet use score on average compared with those who had not gone for an annual health checkup. People who reported that their general health status was poor or fair had about a $22.6 \%$ higher health-related internet use score than those who reported their health status as good, very good, or excellent. The respondents who had participated in a social group had a $12.5 \%$ higher health-related internet use score than that of those who do not participate in a social group. People with a $10 \%$ higher health literacy score had a $3.5 \%$ higher health-related internet use score on average. In addition, health-related internet use scores for people who owned a computer or tablet PC or a mobile phone only were not significantly different from the scores of those without any kind 
of technology device. By contrast, compared with those without any technology device, people who possessed a mobile phone and computer or tablet PC had a $60.0 \%$ higher health-related internet use score, those who owned a smartphone only had a $72.5 \%$ higher health-related internet use score, and those who had a smartphone and computer or tablet PC had an $81.5 \%$ higher health-related internet use score. The $F$ statistic $\left(F_{17,596}=10.30, P<.001\right)$ and $R^{2}$ value $(0.20)$ indicated a good model fit to the data.

\section{Discussion}

\section{Principal Findings}

This study found that better health literacy and greater access to technological devices were associated with higher levels of health-related information-seeking behavior online. We found that the higher the health literacy level and the higher the accessibility to technological devices (eg, access to a mobile phone and computer or tablet PC at home or access to a smartphone), the more likely the respondents were to use the internet to seek health-related information. We also found differences in online health-related information-seeking behavior by sociodemographic characteristics; being female, having a graduate degree, and reporting a poor/fair health status were associated with higher usage of the internet for seeking health-related information.

It is possible that individuals with higher health literacy are more comfortable seeking out health information, are more adept at knowing what to search for and how to find it, and are more comfortable interpreting the information that they access. Our findings about access to technological devices are logical; individuals with more advanced, faster potential for online connectivity are more likely to use those devices for a variety of information-seeking purposes compared with individuals who have more limited access to technology. However, these findings signal a concerning disparity in access to information. As all types of information, including health information, are increasingly delivered online, individuals without access to efficient, effective technological devices are at risk of being left further behind.

The findings about differences in health-related information-seeking by sociodemographic characteristics indicate potential areas of inequity. For example, individuals with graduate degrees were more likely than individuals without college degrees to use the internet for health information. Again, this finding is not necessarily surprising, given already known disparities in access to and use of technology by socioeconomic status, but it could heighten disparities in access to health information $[34,35]$. On many of the individual items measuring online health-related information-seeking behavior, and in the multivariate model predicting ever using the internet for health information (vs never), women were more likely than men to obtain health information online. This may be related to a broader trend of gender differences in health care utilization [36]; however, this also presents an opportunity to implement more strategies to make online health information appealing and useful for men [37].
Additionally, we detected differences by age in online health information-seeking; younger adults and older adults were more likely than middle-aged adults to seek out health information online. For people of all ages who do not access health information online, it is important to ensure that comparable information is easily accessible in other forms. For example, for clinics and hospitals moving toward online-only scheduling and online communication with providers, careful thought should be given to who might potentially be left out and what alternative forms of communication, scheduling, and information delivery can and should be offered. For other sources of online health information (eg, websites, social media, hospital websites), care should be taken to ensure that people of all ages have equitable access to high-quality information, and that people who do not access such information online have equitable access to other forms of information.

\section{Limitations}

This study should be considered in light of its limitations. We relied on a cross-sectional design, which therefore limits the ability to determine causality between online behavior and health literacy. We also did not have a random sample, but rather relied on a sample of adults who attended the Minnesota State Fair and were willing to respond to a survey. Nevertheless, we collected a robust sample capable of detecting meaningful differences in online health-related information-seeking behavior. To the extent that we did not capture a fully representative sample, we are likely to understate the differences we identified. We also did not examine intersectional differences by sociodemographic characteristics (eg, the potential multiplicative impact of gender and age), which should be explored more fully in future research. Finally, although we were able to examine differences in a range of health-related information-seeking behaviors, we were not able to determine the intensity or quality of these online interactions. Not all health information delivered online is good, and more attention should be paid to ensuring high-quality content and to educating the public on how to filter good from bad information.

\section{Practice Implications}

Health information and health care are increasingly being delivered online. Prior research has shown that nearly 4 out of every 5 Americans are currently using the internet for health-related purposes $[10,11]$. Nearly half of the adults in our sample reported using the internet to communicate with their health care provider; more than half used it to look for information about their diet, weight, or physical activity; and more than half used the internet to look for health-related information for someone else. Clearly, the internet plays a large and growing role in how Americans manage and learn about their own health and the health of their loved ones. Thus, the internet has the potential to improve access to health information [9], to reduce barriers in communicating with health professionals [38], and to offer assistance to caregivers [39]. However, our findings also show that the internet is neither universally accessible nor universally used for obtaining health information. More attention needs to be paid to improving access to technology and to offering alternative forms of health information and communication for those without it. This might 
include expanding access to broadband internet and cellular connectivity in rural areas that do not have it; ensuring that public spaces such as libraries have ample access to computers where people can go online, as well as privacy protections for sensitive health information, such as cubby walls or dividers; and providing ample health information through other free sources, including libraries, clinics, and community spaces.

Finally, our study did not measure the quality of the information that individuals receive or the interactions they have. As health care, along with many other sectors of society, increasingly moves online, providers and educators are faced with the enormous task of assisting the public in filtering good information from bad and in advocating for high-quality health information online. This process might start early, in schools working with children on online literacy, but should also expand to include people of all ages, including in workplaces, senior centers, and health care settings.

\section{Conclusion}

In this study, we demonstrated differences in online health-related information-seeking behavior according to the degree of health literacy, access to technological devices, and sociodemographic characteristics. We found that individuals with better health literacy, more access to sophisticated technological devices, and more education are more likely to access health information on the internet. Although these findings may not be surprising, they should be concerning; access to information is an important predictor of behavior $[40,41]$ and disparities in access to health information may exacerbate disparities in health and health care access. Research, policy, and programmatic attention should be paid to improving access to technology, to ensure access to alternative forms of health information for those who cannot or will not access information online, and to improve the quality of online health information.

\section{Acknowledgments}

This research project was jointly supported by the Masonic Cancer Center at the University of Minnesota, Twin Cities, and Research Fund of the Endowed Academic Chair at the University of Alabama School of Social Work awarded to HL.

\section{Conflicts of Interest}

None declared.

\section{References}

1. Meppelink CS, Smit EG, Diviani N, Van Weert JCM. Health Literacy and Online Health Information Processing: Unraveling the Underlying Mechanisms. J Health Commun 2016;21(Sup 2):109-120. [doi: 10.1080/10810730.2016.1193920] [Medline: 27668318]

2. Miller TA. Health literacy and adherence to medical treatment in chronic and acute illness: A meta-analysis. Patient Educ Couns 2016 Jul;99(7):1079-1086 [FREE Full text] [doi: 10.1016/j.pec.2016.01.020] [Medline: 26899632]

3. Matsuoka S, Tsuchihashi-Makaya M, Kayane T, Yamada M, Wakabayashi R, Kato NP, et al. Health literacy is independently associated with self-care behavior in patients with heart failure. Patient Educ Couns 2016 Jun;99(6):1026-1032. [doi: 10.1016/j.pec.2016.01.003] [Medline: 26830514]

4. Bennett IM, Chen J, Soroui JS, White S. The contribution of health literacy to disparities in self-rated health status and preventive health behaviors in older adults. Ann Fam Med 2009;7(3):204-211 [FREE Full text] [doi: 10.1370/afm.940] [Medline: 19433837]

5. Davis TC, Williams MV, Marin E, Parker RM, Glass J. Health literacy and cancer communication. CA Cancer J Clin 2002 May 01;52(3):134-149 [FREE Full text] [doi: 10.3322/canjclin.52.3.134] [Medline: 12018928]

6. White S, Chen J, Atchison R. Relationship of preventive health practices and health literacy: a national study. Am J Health Behav 2008;32(3):227-242. [doi: 10.5555/ajhb.2008.32.3.227] [Medline: 18067463]

7. Murero M, Rice RE. The Internet and Health Care: Theory, Research, and Practice. Milton Park, UK: Routledge; 2013.

8. Rice RE. Influences, usage, and outcomes of Internet health information searching: multivariate results from the Pew surveys. Int J Med Inform 2006 Jan;75(1):8-28. [doi: 10.1016/j.ijmedinf.2005.07.032] [Medline: 16125453]

9. Kalichman SC, Cain D, Cherry C, Pope H, Eaton L, Kalichman MO. Internet use among people living with HIV/AIDS: coping and health-related correlates. AIDS Patient Care STDS 2005 Jul;19(7):439-448. [doi: 10.1089/apc.2005.19.439] [Medline: 16053401]

10. Health Information National Trends Survey (HINTS). National Cancer Institute. 2014. URL: https://hints.cancer.gov/ [accessed 2020-08-15]

11. Internet/Broadband Fact Sheet. Pew Research Center. URL: http://www.pewinternet.org/fact-sheet/internet-broadband/ [accessed 2020-09-01]

12. Cutrona SL, Mazor KM, Agunwamba AA, Valluri S, Wilson PM, Sadasivam RS, et al. Health Information Brokers in the General Population: An Analysis of the Health Information National Trends Survey 2013-2014. J Med Internet Res 2016 Jun 03;18(6):e123 [FREE Full text] [doi: 10.2196/jmir.5447] [Medline: 27260952]

13. Atkinson NL, Saperstein SL, Pleis J. Using the internet for health-related activities: findings from a national probability sample. J Med Internet Res 2009 Feb 20;11(1):e4 [FREE Full text] [doi: 10.2196/jmir.1035] [Medline: 19275980] 
14. Jiang S, Street RL. Factors Influencing Communication with Doctors via the Internet: A Cross-Sectional Analysis of 2014 HINTS Survey. Health Commun 2017 Feb;32(2):180-188. [doi: 10.1080/10410236.2015.1110867] [Medline: 27196037]

15. Rowley J, Johnson F, Sbaffi L. Gender as an influencer of online health information-seeking and evaluation behavior. J Assn Inf Sci Tec 2015 Aug 25;68(1):36-47. [doi: 10.1002/asi.23597]

16. Genuis SK. Constructing "sense" from evolving health information: A qualitative investigation of information seeking and sense making across sources. J Am Soc Inf Sci Tec 2012 Jun 29;63(8):1553-1566. [doi: 10.1002/asi.22691]

17. Harris PR, Sillence E, Briggs P. Perceived threat and corroboration: key factors that improve a predictive model of trust in internet-based health information and advice. J Med Internet Res 2011 Jul 27;13(3):e51 [FREE Full text] [doi: 10.2196/jmir.1821] [Medline: 21795237]

18. Powell J, Inglis N, Ronnie J, Large S. The characteristics and motivations of online health information seekers: cross-sectional survey and qualitative interview study. J Med Internet Res 2011 Feb 23;13(1):e20 [FREE Full text] [doi: 10.2196/jmir.1600] [Medline: 21345783]

19. Fiordelli M, Diviani N, Schulz PJ. Mapping mHealth research: a decade of evolution. J Med Internet Res 2013 May 21;15(5):e95 [FREE Full text] [doi: 10.2196/jmir.2430] [Medline: 23697600]

20. Manganello J, Gerstner G, Pergolino K, Graham Y, Falisi A, Strogatz D. The Relationship of Health Literacy With Use of Digital Technology for Health Information: Implications for Public Health Practice. J Public Health Manag Pract 2017;23(4):380-387. [doi: 10.1097/PHH.0000000000000366] [Medline: 26672402]

21. Wei K, Teo H, Chan HC, Tan BCY. Conceptualizing and Testing a Social Cognitive Model of the Digital Divide. Inf Syst Res 2011 Mar;22(1):170-187. [doi: 10.1287/isre.1090.0273]

22. Zach L, Dalrymple PW, Rogers ML, Williver-Farr H. Assessing internet access and use in a medically underserved population: implications for providing enhanced health information services. Health Info Libr J 2012 Mar;29(1):61-71. [doi: 10.1111/j.1471-1842.2011.00971.x] [Medline: 22335290]

23. Benigeri M, Pluye P. Shortcomings of health information on the Internet. Health Promot Int 2003 Dec 01;18(4):381-386. [doi: 10.1093/heapro/dag409] [Medline: 14695369]

24. Friis K, Lasgaard M, Rowlands G, Osborne RH, Maindal HT. Health Literacy Mediates the Relationship Between Educational Attainment and Health Behavior: A Danish Population-Based Study. J Health Commun 2016 Sep 26;21(Sup 2):54-60. [doi: 10.1080/10810730.2016.1201175] [Medline: 27668691]

25. Berkman ND, Davis TC, McCormack L. Health literacy: what is it? J Health Commun 2010;15(Suppl 2):9-19. [doi: 10.1080/10810730.2010.499985] [Medline: 20845189]

26. Diviani N, van den Putte B, Giani S, van Weert JC. Low health literacy and evaluation of online health information: a systematic review of the literature. J Med Internet Res 2015 May 07;17(5):e112 [FREE Full text] [doi: 10.2196/jmir.4018] [Medline: 25953147]

27. Geboers B, Reijneveld SA, Jansen CJ, de Winter AF. Health Literacy Is Associated With Health Behaviors and Social Factors Among Older Adults: Results from the LifeLines Cohort Study. J Health Commun 2016 Sep 23;21(Sup 2):45-53. [doi: 10.1080/10810730.2016.1201174] [Medline: 27661472]

28. Levin-Zamir D, Baron-Epel OB, Cohen V, Elhayany A. The Association of Health Literacy with Health Behavior, Socioeconomic Indicators, and Self-Assessed Health From a National Adult Survey in Israel. J Health Commun 2016;21(Sup 2):61-68. [doi: 10.1080/10810730.2016.1207115] [Medline: 27669363]

29. Sentell TL, Tsoh JY, Davis T, Davis J, Braun KL. Low health literacy and cancer screening among Chinese Americans in California: a cross-sectional analysis. BMJ Open 2015 Jan 05;5(1):e006104 [FREE Full text] [doi:

10.1136/bmjopen-2014-006104] [Medline: 25564140]

30. Han H, Hong H, Starbird LE, Ge S, Ford AD, Renda S, et al. eHealth Literacy in People Living with HIV: Systematic Review. JMIR Public Health Surveill 2018 Sep 10;4(3):e64 [FREE Full text] [doi: 10.2196/publichealth.9687] [Medline: $\underline{30201600]}$

31. Watkins I, Xie B. eHealth literacy interventions for older adults: a systematic review of the literature. J Med Internet Res 2014 Nov 10;16(11):e225 [FREE Full text] [doi: 10.2196/jmir.3318] [Medline: 25386719]

32. HINTS 4 Cycle 1 Questionnaire. National Cancer Institute (NCI), Health Information National Trends Survey (HINTS). 2014. URL: https://hints.cancer.gov/view-questions-topics/all-hints-questions.aspx [accessed 2020-07-16]

33. Behavioral Risk Factor Surveillance System Questionnaire (BRFSS) Questionnaires. Centers for Disease Control and Prevention. 2016. URL: https://www.cdc.gov/brfss/questionnaires/index.htm [accessed 2020-07-28]

34. Sedrak MS, Soto-Perez-De-Celis E, Nelson RA, Liu J, Waring ME, Lane DS, et al. Online Health Information-Seeking Among Older Women With Chronic Illness: Analysis of the Women's Health Initiative. J Med Internet Res 2020 Apr 09;22(4):e15906 [FREE Full text] [doi: 10.2196/15906] [Medline: 32271152]

35. Gordon NP, Crouch E. Digital Information Technology Use and Patient Preferences for Internet-Based Health Education Modalities: Cross-Sectional Survey Study of Middle-Aged and Older Adults With Chronic Health Conditions. JMIR Aging 2019 Apr 04;2(1):e12243 [FREE Full text] [doi: 10.2196/12243] [Medline: 31518291]

36. Green CA, Pope CR. Gender, psychosocial factors and the use of medical services: a longitudinal analysis. Soc Sci Med 1999 May;48(10):1363-1372. [doi: 10.1016/s0277-9536(98)00440-7] 
37. Venkatesh V, Morris MG. Why Don't Men Ever Stop to Ask for Directions? Gender, Social Influence, and Their Role in Technology Acceptance and Usage Behavior. MIS Quart 2000 Mar;24(1):115. [doi: 10.2307/3250981]

38. Khoong EC, Rivadeneira NA, Hiatt RA, Sarkar U. The Use of Technology for Communicating With Clinicians or Seeking Health Information in a Multilingual Urban Cohort: Cross-Sectional Survey. J Med Internet Res 2020 Apr 06;22(4):e16951 [FREE Full text] [doi: 10.2196/16951] [Medline: $\underline{\text { 32250280] }}$

39. Milios A, McGrath P, Baillie H. A Weekly, Evidence-Based Health Letter for Caregivers (90Second Caregiver): Usability Study. JMIR Form Res 2020 Feb 12;4(2):e14496 [FREE Full text] [doi: 10.2196/14496] [Medline: 32049064]

40. Siedner MJ, Santorino D, Haberer JE, Bangsberg DR. Know your audience: predictors of success for a patient-centered texting app to augment linkage to HIV care in rural Uganda. J Med Internet Res 2015 Mar 24;17(3):e78 [FREE Full text] [doi: 10.2196/jmir.3859] [Medline: 25831269]

41. Janz NK, Becker MH. The Health Belief Model: a decade later. Health Educ Q 1984 Sep 04;11(1):1-47. [doi: 10.1177/109019818401100101] [Medline: 6392204]

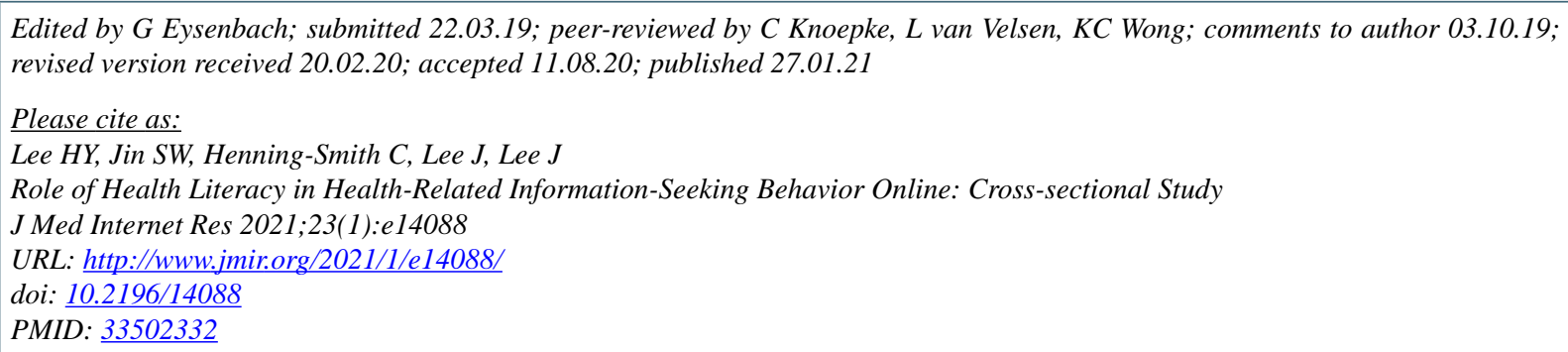

(CHee Yun Lee, Seok Won Jin, Carrie Henning-Smith, Jongwook Lee, Jaegoo Lee. Originally published in the Journal of Medical Internet Research (http://www.jmir.org), 27.01.2021. This is an open-access article distributed under the terms of the Creative Commons Attribution License (https://creativecommons.org/licenses/by/4.0/), which permits unrestricted use, distribution, and reproduction in any medium, provided the original work, first published in the Journal of Medical Internet Research, is properly cited. The complete bibliographic information, a link to the original publication on http://www.jmir.org/, as well as this copyright and license information must be included. 